\title{
IDENTIDADES NACIONALES Y OTRAS IDENTIDADES
}

\author{
GÖRAN THERBORN ${ }^{(*)}$
}

\section{RESUMEN}

El presente trabajo aborda tres temas. Primero, las identidades nacionales insertas en una teoría general sobre el proceso de formación de la identidad y de sus efectos sociales. Segundo, se argumenta que el peso relativo de la identificación nacional depende de las articulaciones con el Estado; se presentan e ilustran variaciones en las relaciones Estadosociedad y Estado-Estado. El argumento dice relación con la teoría del Estado y las relaciones internacionales así como con las identidades nacionales. Tercero, los rituales y simbolismos nacionales son considerados como indicadores de la identificación nacional y del nacionalismo. A modo de ilustración se mencionan las variaciones entre los países en los feriados nacionales y en la arquitectura de la ciudad capital. El presente trabajo forma parte de una investigación en curso sobre los rituales y el simbolismo nacional así como sobre teoría social.

\section{PROPÓSITO}

Elaborar una teoría general y una comprensión/aprehensión de los hechos contemporáneos, del ritual y de la "realpolitik".

La nación y sus derivados, nacionalismo, nación-nación, etc., se encuentran entre los fenómenos subteorizados más importantes del mundo moderno y, por tanto, también del postmoderno. Ciertamente, estas materias han atraído la atención de un gran número de historiadores y cientistas políticos y también, en años recientes, de antropólogos y estudiantes de literatura. Sin embargo, en la teoría social general, la nación no ha alcanzado la plena ciudadanía, ni siquiera el derecho a una residencia segura. Desde un punto de vista teórico. la nación aguarda su tarjeta verde.

Resulta sintomático que las principales contribuciones sociológicas al estudio de las

$\therefore$ Departamento de Sociología, Universidad de Göteborg. Suecia 
naciones y del nacionalismo -realizadas por Anthony D. Smith y Bernard Giesen-revisten una orientación predominanteinente histórica.

Uno de los objetivos centrales de este trabajo es, entonces, señalar cómo la nación puede ser productivamente comprendida, teonzada y analizada -como una instancia de la teoría social general-como una forma de identidad. Mi enfoque del tema es distinto - pero no necesariamente antagónico-de la perspectiva de la elección racional de Michael Hechter.

Por cierto, no ha escapado a los estudiosos de las naciones la variabilidad de las concepciones sobre lo nacional y los nacionalismos. De hecho, desde que fueron formulados dichos conceptos en los años 40 , se han constituido en un capital de intercambio entre especialidades. Sin embargo, la variabilidad ha sido buscada y encontrada principalmente en el pasado y muy poco en el presente. El interés reciente sobre los distintos criterios contemporáneos en -o las condiciones de- la ciudadanía está más al día pero es mucho más restringida en su foco nacional.

Un segundo propósito central de esta contribución, entonces, es sugerir patrones de variabilidad actuales en el sentido e identificación de las personas con la nación. Un enfoque productivo para llegar al auge y caída de identificaciones rivales, es la concepción materialista de la ideologíal. Esto nos lleva a examinar cómo se articula la nación con el Estado. Para hacerlo, a su vez, debemos encontrar una forma que nos permita analizar el Estado tanto en las relaciones internacionales cuanto en relación a la sociedad civil interna. Esto nos llevará a visualizar las teorías de la 'globalización' y del 'Estado'.

Las ceremonias, los rituales, los símbolos, los monumentos, las puestas en escena, los apelativos, siempre han sido cruciales en el imaginario colectivo que sustenta a las comunidades de las naciones. Sin embargo, sus variaciones contemporáneas casi no han sido estudiadas en forma sistemática. Aún menos se ha relacionado el ritual y el simbolismo nacional con la teoría general social y política. Por último, insinuaremos cómo las ricas fuentes de los ritos y símbolos, incluyendo la arquitectura de la ciudad capital, pueden ser examinados con miras a lograr un cuadro más claro del poderoso pero esquivo fenómeno de la identificación nacional y del nacionalismo.

En relación a esto, nuestro punto de partida teórico será una lectura ecuménica de la teoría sociológica del análisis ${ }^{2}$. De acuerdo con ella los seres humanos actúan en universos de significados $o$, en otras palabras, los actores pertenecen a culturas, 'pertenencia' que puede ser deliberadamente elegida. Los actores también se sitúan en patrones de recursos/ oportunidades y de limitantes/riesgos; en otras palabras, los actores se localizan en estructuras. El peso relativo de cada uno de ellos está constantemente sujeto a controversias entre las nociones más 'idealistas' o 'culturalistas' y las más 'materialistas' o instrumentales'. Ello. a pesar del hecho de que los autores más serios perciben la existencia de alguna interacción entre ambas. Más aún, la teoría social no sólo trata con actores sino que también con sistemas. Pero los sistemas sociales son culturales o estructurales o ambos interactúan entresí.

\footnotetext{
G. Thethern. "The Ideology of Power and the Power ol ldcology". London, NLB. 1980

G Thom. Sociology as a Discipline as Oisagrements and as a Patadign of Conpeting Explanations". en P. Sztonphit

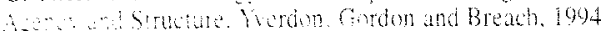


La nación constituye un sistema cultural. Sin embargo, el aspecto más interesante no es su carácter asistemático sino hasta qué punto los actores pertenecen a él o hasta qué consecuencias. Tanto la nación como un sistema cultural y los actores que pertenecen a ella se localizan en una estructura de recursos y de limitaciones. Más adelante veremos como una localización estructural variable puede afectar el significado de la pertenencia nacional.

La nación es una manifestación de una de las dos variables maestras de la sociología en el esfuerzo por explicar la acción, la pertenencia cultural. Como tal, la primera también puede ser analizada en sus aspectos cognitivo y valorativo. Pero es la nación, como un tipo de identidad, la que despierta mayor interés y la que aparece como más prometedora.

\section{PROCESOS DE FORMACIÓN DE LA IDENTIDAD: PROCESOS NACIONALES Y OTROS.}

La identidad es un concepto universal de las disciplinas culturales, conductuales y sociales, que se extiende desde la filosofía y la psicología de la personalidad a la macrosociología -curiosamente olvidada en la teorización sociológica reciente. Como un problema de la identidad, la nación y el nacionalismo deberían ser estudiados de la misma manera como, por ejemplo, la personalidad, las profesiones, los grupos de interés, los movimientos de identidad y la así llamada, en la actualidad, política de la identidad.

Tres son los procesos básicos involucrados en la formación de la identidad, sea ésta individual o colectiva:

\section{Diferenciación}

Auto-establecimiento

Reconocimiento

La diferenciación se refiere a la separación entre el potencial 'yo' o 'nosotros' y el medio ambiente. Al margen de la psicología infantil es útil tener presente que la diferenciación se puede iniciar a través del otro o del sí mismo. Los otros pueden diferenciarlo a uno así como uno puede diferenciarse de los otros. El proceso mismo de diferenciación tiene dos aspectos, las experiencias del otro y el descubrimiento del sí mismo ${ }^{3}$.

Bajo condiciones similares, podemos suponer que mientras más claramente puedan ser visualizados los otros y mientras más distintos sean, la identidad separada emergerá más tempranamente y será más fuerte. Por otro lado -ya que nos estamos refiriendo a experiencias- también se da la otra relación, es decir, mientras más claro sea el sí mismo, bajo iguales condiciones más clara será la diferencia con el otro. Es debido a esto último que los países nórdicos, sociedades relativamente mas igualitarias desde el punto de vista socio-económico, exhiben el sentido de identidad de clase más fuerte de Europa.

La experiencia de la alteridad del otro se relaciona íntimamente en forma irreductible con el descubrimiento y la construcción del sí mismo. La separación de los otros cercanos constituye un rasgo en la construcción del si mismo. Además de la experiencia con los otros,

${ }^{3}$ Cómo este último es afectado por el prunero es un problema central de la teoría de desarrollo psicologico así como los padro que actúan como tales. En la formación de las identidades colectivas esa relación es comúnente menos irilrincada. porąue ambo

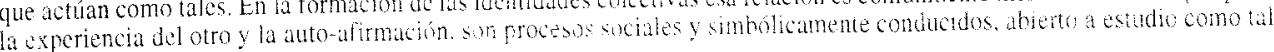


este proceso de auto-asertividad aparece dirigido por el crecimiento de los recursos internos, sean éstos del individuo, de un conjunto de practicantes ocupacionales o de una comunidad histórica potencial. Es decir, bajo condiciones iguales, mientras más recursos existan mayor será la demanda de autonomía independiente.

Estimo que esto se aplica a la dinámica de la personalidad y, a la larga, a la historia de las profesiones y de los estados-nación, hecho que se ha manifestado en forma reciente en la vanguardia de los países bálticos y en Slovenia y Croacia, con el quiebre de lá URSS y de Yugoslavia. En épocas anteriores, pareciera ser que la acumulación relativa de los recursos culturales y políticos modernos tiene sentido en el marco de los grandes rasgos de la historia de la des-colonización, comenzando por las sociedades de colonos de los nuevos mundos, continuando con la conquista de las culturas altas de Asia; luego, empezando en Africa desde el norte y el oeste seguido, sólo mas tarde, por Papúa Nueva Guinea.

La diferenciación es un proceso muy disparejo a lo largo del tiempo. Involucra algunos momentos de ruptura y, entremedio, sedimentos duraderos de percepciones del sí mismo y del otro. En el campo de las identidades colectivas, los momentos más dramáticos de ruptura de la identificación son las guerras y el quiebre de un orden estatal dado.

En segundo lugar, la identidad no debe ser concebida sólo como una vaga negación del otro. También es, normalmente un elemento positivo, una identificación con alguien o algo. luego, por supuesto, de la conciencia de la separación. Con una venia al gran sociólogo Robert Merton y a su teoría de los gnupos de referencia, podemos referirnos a este segundo aspecto de la formación de la identidad como el establecimiento de la auto-referencia o de las auto-imágenes (incluyendo la posibilidad de que éstas sean numerosas), en breve, el auto-establecimiento. Este se utiliza para denominar el resultado del proceso que se produce, sea a través de una auto-selección deliberada, una socialización del otro -también deliberada- $o$ a través de un proceso subconsciente de adaptación. Debieramos pensar en este proceso como temporalmente disparejo, como marcado por un reducido número de eventos decisivos cuyos efectos son duraderos.

En la formación de las identidades, cuatro tipos de auto-referencias han demostrado ser centrales. Estos dicen relación con: origen, residencia, competencia o con valores. Dicho en otras palabras, pareciera ser que lo que más importa es de dónde viene la persona, dónde está, qué es lo que hace y en qué cree. Alguien puede ser el padre de su hija, miembro de un linaje, originario de un pueblo o un país; en forma alternativa puede ser o haberse convertido en la esposa de su marido, o el residente de un lugar al cual se ha trasladado a vivir. La identidad también puede residir en la competencia, en una cierta ocupación y educación o en el tener alguna habilidad o hablar un idioma determinado. Mas aún, la imagen de sí mismo puede estar formada, de manera significativa -tal vez abrumadora- por los valores en los cuales la persona cree, la religión, las ideas políticas o el estilo de vida.

Con estos cuatro tipos de auto-referentes no se agota la lista de posibles identidades, ni se trata de tipos mutuamente excluyentes. Sin embargo, su frecuencia a lo largo del espacio y del tiempo y su aplicabilidad tanto a la identidad colectiva como a las identidades individuales sugieren que los sí mismos producidos por los procesos psicológicos y sociales de formación de la identidad, en toda su inmensa variedad, conforman patrones comprehensibles. 
Finalmente, la auto-identidad depende del otro, no sólo al separarse de él o de ella sino también al ser reconocido. El reconocimiento es el tercer proceso crucial en la formación de la identidad. En las controversias actuales en torno a las identidades étnica y sexual. la 'política del reconocimiento', ha sido puesta en el centro de las discusiones. Así ocurre también en la teoría sociológica de las profesiones, en la cual el estado de reconocimiento de la identidad de una categoría particular de personas, como los únicos poseedores legítimos de cierto tipo de conocimientos, es considerado como crucial. El reconocimiento es menos prominente en la psicología del desarrollo, la teoría de la socialización y las concepciones sobre la conciencia y sólo se le postula como concepto en la teoría de los roles. La lucha por la 'auto-determinación nacional', la cultura nacional, la autonomía y la independencia constituyen luchas en pro del reconocimiento.

Deberíamos esperar que todas las identidades se vean significativamente afectadas por el reconocimiento o el no-reconocimiento por parte de los otros. Para decirlo de modo terminante, bajo condiciones similares, una identidad que no es reconocida por otros no funciona propiamente como identidad y es socavada. Es verdad que este reconocimiento puede no asumir la forma explícita de un apelativo respetuoso, como de Señora Trabajadora o Señor Extranjero sino una forma implícita y/o despectiva.

Una teoría sobre la formación de la identidad, entonces, debería buscar los determinantes de la diferenciación, de la oferta y demanda de los objetos de referencia y un reconocimiento positivo o negativo.

\section{LA DINÁMICA DEL PROCESO.}

Las identidades se generan a través de experiencias, algunas de las cuales constituyen experiencias cruciales que hacen que la persona viva una variedad de situaciones desde una misma (idéntica) perspectiva. En otras palabras, las identidades tienden a poseer una dinámica particular caracterizada por momentos relativamente breves de formación seguidos por períodos más largos de duración de la identidad.

En la psicología de la personalidad, los momentos formativos se ligan a situaciones de crisis. Las crisis pueden ser las propias del ciclo de vida humano, definidas tanto social como biológicamente desde la temprana infancia hasta la adolescencia, y del término de la educación media hasta la formación de la familia, la crisis de la vida adulta y la jubilación. Las crisis también pueden originarse en contingencias externas al individuo, tales como un accidente o enfermedad, la muerte de alguien cercano, el desempleo, la guerra, las humilaciones, etc. Las crisis de identidad también pueden surgir desde dentro por razones inescrutables y expresarse en preguntas tales como ¿es ésta la vida que realmente quiero/ queremos vivir? Las crisis de la identidad nacional son generalmente crisis del Estado, de la derrota o la disolución política, pero también han sido producidas, por ejemplo, por cambios sociales significativos en las sub-poblaciones de un estado determinado, como es el caso reciente de Flandes o Quebec.

La dinámica discontinua de los procesos de identidad hace que las cohortes o generaciones sean cruciales. Las transformaciones sociales afectan las identidades probablemente más que nada en sentido demográfico. Las cohortes mayores tienden a perder su compás, su 
confianza y habilidad de liderazgo, su fuerza y, finalmente, mueren. Al mismo tiempo, una crisis importante, u otros cambios sociales, constituyen la experiencia formativa de las nuevas cohortes, las que se fortalecen del espiral virtuoso de sentirse a tono con los tiempos.

El crecimiento, las crisis, las cohortes experienciales afectan la demanda por la identidad. Pero la oferta aparece como un aspecto también importante de la dinámica.

En cualquier momento y en cualquier universo de significados, tiende a haber una oferta limitada y estructurada de modelos significativos de identidad tanto colectivos como individuales. En las sociedades modernas, la oferta parece regirse por una dinámica discontinua de avances o caídas significativas, poniendo en movimiento anillos de difusión.

Las identidades nacionales, por ejemplo, irrumpieron con la Revolución Francesa, se agudizaron con las guerras napoleónicas y fueron silenciadas o permanecieron latentes bajo el apogeo de la Santa Alianza. Luego se produjo un nuevo avance a mediados del siglo XIX que llegó a su punto culminante en 1914, seguido por un recambio de resentimientos en los tratados de paz de la Primera Guerra Mundial y la Depresión que le siguió. El resultado de la Segunda Guerra Mundial desacreditó el nacionalismo y a las fuertes identificaciones nacionales en Europa y Japón. En oposición al imperialismo occidental, la identidad nacional y el nacionalismo se nutren en forma creciente a lo largo de la zona colonial de Africa y Asia. Actualmente se encuentran a la defensiva ante los avances tanto del neoliberalismo occidental como de la religión islámica.

La provisión de identidades no viene del cielo sino que se produce y es suministrada por los 'empresarios de la identidad', periodistas, profesores, pastores, organizadores, etc. Su papel crucial en el surgimiento del nacionalismo ha sido extensamente estudiado.

\section{EFECTOS DE LA IDENTIDAD.}

La identidad es importante en la vida social no porque se trata de una variable dependiente que despierta curiosidad, sino porque es una poderosa variable independiente y causal. Sin embargo, como tal, ha aparecido en forma muy discreta en la historia de la sociología.

La identidad afecta en forma significativa a los otros dos componentes básicos de la cultura, el componente cognitivo y el evaluativo.

Las bases elementales de la sociología del conocimiento nos llevan a esperar que la identidad afecte la percepción que la persona tiene del mundo, al hacer que algunos de los rasgos de este último sean más pertinentes que otros. Al ser nacionalista, la persona tiende a prestar más atención y a percibir en mayor grado los fenómenos que dicen relación con la nación, su fuerza y honor, las oportunidades y los riesgos. También se espera que la identidad afecte la confianza y la credibilidad. Bajo condiciones similares. tiendo a confiar más en lo que alguien como yo dice o hace, que en los demás.

Más aún, la identidad determina el ámbito de la racionalidad. El significado de la búsqueda del auto-interés depende de quien sea este 'si mismo'. ¿sólo yo mismo?. ¿mis 
padres y yo?, ¿mi esposo y yo?, ¿mis hijos y yo?, ¿mis padres, mi esposo, mis hermanos y yo?, ¿mis compañeros de curso y yo?, ¿mis compatriotas y yo?. Cuidar el 'interés nacional' es lo racional para aquellos que se identifican con la nación en cuestión.

La identidad tiene al menos dos efectos muy importantes sobre las normas. El primero fue puesto de relieve por Robert Merton. El objeto de referencia con el cual la persona se identifica constituye una importante fuente de normas y valores. Las personas acatan las normas porque son dependientes de otros o monitoreados por otros, pero también -y más que nada- porque se identifican con otros. Es decir, la identidad puede constituir una explicación para dar cuenta de por qué ciertas poblaciones suscriben determinadas normas y valores. En el caso de las identidades nacionales, este efecto puede comprometer, por ejemplo, las normas sobre las actividades antinacionales adecuadas e inadecuadas

En segundo lugar, la identidad determina el rango de las normas. Dentro del rango de identificación, la muerte constituye una suerte de suicidio, la negativa a ayudar a otra persona es un tipo de autonegación. Fuera de dicho rango, en relación al Otro, puede ser muy legítima, incluso un deber, una defensa legítima, una guerra justa.

\section{LA NACIÓN Y LAS POLÍTICAS RIVALES DE LA IDENTIDAD.}

El nacionalismo es un tipo de 'política de identidad' que afirma la decisiva primacía de lo nacional por sobre otras identidades. Como todas las otras actividades humanas en la sociedad, la política de la identidad se sitúa en el tiempo y en el espacio. Dentro de estas coordenadas tiempo/espacio dos son los determinantes que pesan sobre las posibilidades y la destreza estratégica: el campo cultural de las identidades en competencia y el anclaje estructural de las identidades pertinentes en la distribución de los recursos y limitantes, del poder institucionalizado, del dinero y/o de la violencia.

Históricamente, los principales competidores de la nación como una identidad colectiva parecen haber sido la tribu, la religión, la ocupación (incluyendo la herencia y la casta), la localidad (villa, pueblo, provincia), la clase, la raza y -en forma más reciente- la ideología y el estilo de vida. En los tiempos modernos se agrega un nuevo elemento al calor de las identidades colectivas rivales, el de las identidades individuales y de visualizar a las colectividades sólo como agregados de individuos (o de familias).

¿Bajo qué condiciones y por qué es probable que un tipo de identidad sea más fuerte que otro/s tipo/s? La mejor manera y la más fácil de contestar esta pregunta es echando una mirada a las implicancias estructurales de las identidades en cuestión. En condiciones similares, esperaríamos que las identidades que se conectan con recursos/oportunidades más afirmadores y/o con limitantes/riesgos que implican mayores sanciones, sean más atractivas que aquellas que se conectan con menos recursos y limitantes. Es preferible concebir los procesos de identificación como ocurriendo dentro de una matriz de afirmaciones y sanciones estructurales.

Dejando de lado la jerga académica, podríamos decir que cuando las identidades compiten, aquella que exhibe los mejores prospectos y/o se conecta con el poder más fuerte, es la que tiene la mejor oportunidad de ganar nuestra adhesión. No nos detendremos aquí en las 
calificaciones y especificaciones que podrían ser necesarias; el punto al que queremos llegar lo antes posible es éste: el poder y la intensidad de las enculturaciones nacionales depende primariamente de cómo la nación, como construcción cultural, se liga con el Estado, con las estructuraciones que el Estado hace de los recursos y de las limitaciones. El Estado puede existir, o bien puede ser una construcción hacia la que se tiende.

Ante la imposibilidad de abordar, dentro de los límites de este trabajo, el posible anclaje estructural de las identidades en competencia, nos concentraremos en las conexiones entre la nación y el Estado; éstas son mas variables de lo que se suele pensar.

\section{RELACIONES SOCIEDAD-ESTADO Y ESTADO-ESTADO.}

Las relaciones nación-Estado revisten dos dimensiones principales. Una, se refiere a las relaciones Estado-sociedad o, mejor dicho, al tipo de relaciones entre, por un lado, un Estado y, por otro lado, su población y su territorio. La segunda dimensión dice relación con la forma en que un Estado determinado se relaciona con otros estados.

La noción cotidiana de Estado-nación encubre una variación significativa en las relaciones Estado-sociedad. Para nuestros propósitos, una sociedad contemporánea basada en el Estado dentro de fronteras, puede ser políticamente percibida como un agregado de individuos (y de familias y organizaciones) y sus intereses. En el otro polo, puede aparecer como una colectividad única, como una Nación con $\mathrm{N}$ mayúscula. Las principales tareas del Estado pueden ser concebidas como el manejo de los intereses legítimos de sus ciudadanos, o bien como construcción, desarrollo y defensa de la Nación. Las dos dimensiones tienden a aglutinarse de modo tal que en lugar de tener cuatro alternativas lógicas, tendemos a obtener dos tipos polares de un continuo: los estados administradores de las sociedades civiles y los estados promotores de Naciones. En los primeros, la identidad nacional es débil, de tono menor o latente; en los segundos, la identidad es fuerte y manifiesta.

Pueden ser leídos empíricamente desde -y operacionalizados por- la presencia/extensión/ausencia de una política nacional simbólica por parte del Estado, expresada en la escolarización, la promoción cultural y los rituales del mismo.

La prevalencia de una o de otra, depende históricamente de las trayectorias, determinadas por cómo y cuándo el país en cuestión alcanzó una política moderna y por las experiencias modernas.

Entre las cuatro entradas históricas a la modernidad ${ }^{4}$, se podría esperar que las identidades nacionales sean más fuertes -al menos en el sentido de estar más omnipresentes en la población- en las naciones políticamente discontinuas de Europa que en los nuevos mundos y en la zona ex-colonial. También debería ser más fuerte que en las naciones que se mueven lentamente desde un punto de vista social con una modernización inducida desde el exterior, tales como la China pre-comunista, Tailandia o Irán, sin mencionar Afganistán o Etiopía. Pero también se podría esperar que los países con una modernización rápida inducida desde fuera, es decir, de discontinuidad social como Japón y Turquía, desarrollaran identidades

\footnotetext{
‘ Ver G. Therborn. 'Routes to/through Modernity', en M. Featherstone, R. Robertson, and S. Lash (eds.), Global Modernities
} London. Sage. 1995. 
nacionales fuertes. En esta etapa mi teoría no puede decir cómo se comparan estos últimos países con los resultados de las rupturas políticas en Europa en el umbral de la modernidad.

Las discontinuidades políticas y sociales allí ejemplifican las crisis de identidad. El argumento de la discontinuidad política en Europa se refiere a la nación como una unidad de ruptura puesta en contra del dominio de las dinastías. El primer ejemplo es Francia, pero la lista es larga: desde Italia y Alemania, a Noruega, Europa central oriental e Irlanda. La discontinuidad social del Japón de la restauración o de la Turquía Kemalista comprenden casos de cambio social por ruptura en donde las naciones fueron construidas para apoyar a los poderes.

La heterogeneidad inherente (especial) de las nuevas naciones de colonos, nativos y (ex)esclavos y las fronteras socialmente arbitrarias de la zona ex-colonial, deberían llevarnos a esperar que las crisis de identidad de la independencia se hubieran traducido en efectos muy disparejos en términos de la identidad.

Se esperaría que las antiguas políticas europeas, con ninguna o escasas rupturas culturales en su camino a la modernidad, manifestaran una menor identidad nacional: Dinamarca, los Países Bajos, Suecia, Suiza, el Reino Unido. Tampoco debiera hacerlo Austria, a pesar de su trauma de 1918-19, en tanto se convirtió en nación sólo a través de la derrota y el error.

Además de la variación de la articulación Estado-sociedad, la prominencia y el significado de las identidades nacionales varía con lo que podemos llamar la ubicación sistémica del Estado, es decir, la ubicación de un Estado dado dentro del sistema de estados. Este último no debe ser visto sólo como un sistema mundial sino también como involucrando un conjunto de subsistemas regionales de extensión variable y de un grado de superposición también variable.

De estos sistemas -el global y el regional- existe sólo un aspecto directamente pertinente al tema de las naciones; es decir, si un Estado determinado es o no parte de un conjunto competitivo de estados. Dichos conjuntos pueden ser globales, de poder mundial, hegemonía o 'liderazgo' mundial, regional o local, compuesto de dos rivales que compiten por un determinado territorio o por algún otro premio.

La mayor parte de los estados actuales no son de ninguna manera miembros de un conjunto competitivo; cuando más lo son marginal y ocasionalmente. El gran juego de poder de la política global se simplificó después de la Segunda Guerra Mundial convirtiéndose en una díada de superpoderes, uno de los cuales ya ha desaparecido. Si Estados Unidos tiene algún proyecto de poder mundial, más allá de prevenir el surgimiento de cualquier otro poder mundial, es un tema poco claro y abierto a la controversia. Existen escasos jugadores regionales poderosos: Rusia, China, Francia y, recientemente, Alemania; en un futuro cercano posiblemente existirán otros pocos. Existen algunas regiones en donde se producen rivalidades de Estado: la ex-Yugoslavia, el Cáucaso, el Oriente Medio, por ejemplo. Y existen algunos conjuntos locales, la mayor parte de ellos ubicados en Africa y Asia, aunque ocasionalmente surgen conflictos temporales entre estados en América Latina y en el área del Atlántico norte (por las aguas territoriales). 
Las relaciones inter-estados, a las cuales nos referimos aquí para explicar las variedades de identificaciones nacionales, derivan principalmente de la variabilidad de recursos de los estados y de procesos de equilibrio de poder a nivel global, regional y local.

Al combinar las relaciones Estado-sociedad y Estado-Estado obtenemos la siguiente situación, de la cual se pueden esperar distintos tipos de identidad nacional y de nacionalismos

\section{DETERMINANTES DE LA IDENTIFICACIÓN NACIONAL.}

Ubicación del estado

En un Estado en competencia

Fuera de un Estado en competencia
Relación Estado-sociedad

Construcción de la nación Administración social

A medida que pasamos del casillero 1 al 4, la identidad nacional tenderá a disminuir, a ser menos intensa y asertiva. Los procesos de diferenciación y de reconocimiento tenderán a desaparecer. El nacionalismo, de una fachada ostentosa se tornará latente o en extinción.

La identidad nacional del tipo 1, producto de la construcción competitva del Estado, se ejemplifica a partir de: el caso de Prusia y las guerras de liberación, Alemania durante el segundo y el tercer Reich, Japón desde la restauración Meiji hasta 1945; los Balcanes desde cerca de mediados del siglo XIX hasta 1945, la ex-Yugoslavia desde cerca de 1990, con Eslovenia quizás pasando al casillero 3; la mayoría de las nuevas repúblicas de la ex-URSS, sobre todo en el Cáucaso; el Oriente Medio después de 1948; en forma menos clara el subcontinente indio. Después de la Segunda Guerra Mundial, Francia ha pasado del casillero 1 al 2 sin llegar totalmente a este último. En una ubicación intermedia similar parecerían encontrarse la mayor parte de los países de Europa Central Oriental, desde Polonia a Bulgaria.

El casillero 2, que contiene los estados en competencia socialmente administrados, parece estar completo con la presencia de Estados Unidos y con China y Rusia ubicados en las esquinas. En verdad, cada uno de estos países ostenta un cierto grado de simbolismo de nación-Estado, el juramento a la bandera en los colegios de Estados Unidos, por ejemplo. También estuvo el Reino Unido todo el tiempo hasta Suez para luego moverse en la dirección del cuarto tipo. La mayoría de los estados nación de Europa post 1990-1991 se dirigen hacia el casillero 3 o esperan hacerlo. Allí se encontrarán con una buena parte de las naciones de Africa, algunas de las cuales depositan sus esperanzas en la opción 4 . Será necesario mirar con mas detención países como Irlanda y Noruega, Chile y México, para precisar si deben ubicarse en el casillero 3 o el 4.

En el último casillero, con estados como administradores sociales internos principalmente, se ubican, de manera firme y por un largo período, países como Dinamarca, los Países Bajos, Suecia y Suiza, rodeados, a distancias variables, de las naciones de Europa Occidental y central del tamaño de Italia o del Reino Unido, o más pequeños, y la mayoría de los países del nuevo mundo. Aunque sus empresas comerciales son competidores entusiastas y formidables en el mercado mundial, Japón, después de 1945 y la República Federa! 
Alemana, se han situado al margen de la carrera de los estados. Sin embargo. en Alamania existe, desde 1990, una creciente voluntad de la elite política para aprestarse a la lucha. mostrar los brazos armados del país, los operativos militares para la 'mantención de la paz internacional y de actuar como el patrón de la clientela de Europa Oriental. En términos del esquema señalado, Alemania está lentamente -y hasta ahora cautelosamente- pasando del casillero 4 en dirección al casillero 2 .

Estimo que esta distinción entre participar en -o la sujeción a- los mercados globales : el estar comprometido en la competencia o rivalidad entre los estados, puede aportar algún peso al debate general sobre el estado nación y la globalización. En el contexto aquí considerado, sin embargo, el punto es que los cuatro casilleros identificados pueden dar cuenta de la identificación nacional y del nacionalismo. Cabe hacer notar que el posible provecho de la tipología sugerida más arriba es independiente del grado de corrección empírico con el cual se ha realizado la ejemplificación de los países.

La anterior es una hipótesis que, sin embargo, no será puesta a prueba en este trabajo: Tal como lo verá el lector por sí mismo, la hipótesis tiene cierta plausibilidad, ello se hará evidente a partir de una breve mirada comparativa a los rituales y al simbolismo de la identidad nacional.

\section{UNA LECTURA DE LA NACIÓN: RITUALES Y ARQUITECTURA DE LA CIUDAD CAPITAL.}

Las identidades tienden a poseer una dimensión simbólica importante, en gran parte derivada del hecho de ser una relación entre un sí mismo y un mundo exterior, una distinción entre el yo/nosotros y ellos. Hoy en día -y tradicionalmente- la identidad de la persona con frecuencia se expresa en una forma particular de vestir, de peinarse y en otras formas de apariencia externa.

El simbolismo y el ritual son especialmente importantes para las identidades colectivas en tanto operan para señalar y expresar la pertenencia común de sus miembros a la vez que manifiestan los límites entre los miembros y los no miembros. Los ritos de iniciación, las reuniones periódicas y focalizadas de los miembros, las ceremonias especiales, las conmemoraciones y las celebraciones, las banderas y otras insignias, los uniformes y las procesiones, juegan un papel importante en la expresión de las identidades colectivas. Su frecuencia, tamaño o difusión y su contenido, pueden ser utilizados como indicadores del carácter y de la fuerza de las identidades colectivas, las cuales son difíciles de identificar si se considera a los individuos por separado5.

Los feriados nacionales emergieron con la nación, primero en Estados Unidos con las celebraciones del 4 de julio desde 1777 y en Francia en donde el 14 de julio se convirtió en un festival de la nación en 1790 y en un día nacional a partir de 1880. La forma que revisten esas fechas puede ser usada como una lectura ritual de la nación y como una manifestación tangible de una identidad nacional colectiva.

En la Europa contemporánea, el 14 de julio francés es sui generis, es el único feriado

${ }^{5} \mathrm{G}$. Therborn, European Modernity and Beyond, London, Sage, 1995. pp. 233ff. 
nacional que actualmente se celebra con pompas militares en Europa Occidental -la celebración de la Revolución Rusa en la ex-Unión Soviética, el 7 de noviembre, era el único equivalente real del 14 de julio en la Europa de post-Guerra- y al mismo tiempo, se trata de un festival popular. La Gloria de la Nación se manifiesta y se venera en la mañana bajo la forma de un desfile popular, en tanto que en la noche -tanto antes como después- las personas se divierten en las colectividades más pequeñas que sociológicamente conforman la nación.

Por contraste, los británicos ni siquiera tienen un feriado nacional, las cuatro naciones que conforman el Reino Unido tienen, eso sí, un día en que celebran a sus respectivos santos patronos. Sin embargo, en primer lugar ello constituye un anacronismo británico especial en un país moderno, predominantemente protestante y, en segundo lugar, al menos en la nación mas grande, Inglaterra, casi no se celebra.

El día nacional oficial en la Italia de post-Guerra, 2 de Junio, remite al referendum de 1946 que abolió la monarquía. Comprensiblemente, no es un día de mucha preocupación nacional, pero al menos en el norte de Italia, el 25 de Abril, el Día de la Liberación que conmemora el último levantamiento anti-facista en 1945, constituye una ocasión para la expresión de manifestaciones masivas.

Alemania Occidental no tenía un feriado nacional, aunque utilizó el levantamiento de los trabajadores de Alemania Oriental en 1953 como el Día de la Unidad Alemana (17 de Junio). Después del término de la República Democrática Alemana, el Día de la Reunificación se celebra el 3 de octubre.

El año 1945 constituye un quiebre brusco en la historia de la identidad nacional alemana, originalmente una de las más asertivas del mundo. Estudios de post-Guerra hasta 1990 inclusive, muestran que los alemanes tienen el menor orgullo nacional de todos los países, seguidos por los holandeses y los japoneses. La voluntad de pelear por el propio país también es débil entre los principales perdedores de la Segunda Guerra Mundial; la más débil de todas es Japón, seguido por Italia y Alemania ${ }^{6}$.

El destino de la obra de teatro Die Hermannschlacht (La Batalla de Hermann) es sintomática del proceso de devaluación del simbolismo nacional y de la identificación en Alemania posteriores a 1945. Escrita por Heinrich von Kleist en 1809 como parte de la guerra anti-napoleónica en Alemania, la obra rinde tributo a un jefe guerrero alemán, Herrmann (o Arminius) quien, en el año 9 A.C., derrotó a un ejército romano en el noroeste de Alemania. La obra se convirtió en una expresión importante del nacionalismo alemán a mediados del siglo XIX y posteriormente, tanto en el Reich de Guillermo como en el Reich nazi. Después de 1945, se la consideró como comprometida, demasiado nacionalista y no fue puesta en escena sino hasta 1982. La nueva ambientación de la Batalla de Hermann fue un gran éxito tanto entre los críticos como entre el público, pero la obra ya no era nacionalista ni glorificaba las fuerza armada, ahora se presentaba como anti-imperialista y como un estudio sobre la violencia. El guerrero alemán aparecía como 'una mezcla de Heinrich Böll y el Che Guevara', con boina y en impermeable ${ }^{7}$.

Las naciones pequeñas, con países al margen de todas las peleas entre estados, también

G. Therborn. European Modernity and Beyond. London. Sage, 1995, pp. $278 \mathrm{ff}$

A. Dörner. Politischer Mythos und symbolische Politik, Oplade. Westdeytseger Verlag. 1995, pp. 370ff. 
pueden poseer y evidenciar un fuerte sentimiento de identidad nacional si su independenciat se ha producido en forma tardía y si han luchado arduamente por ella. Los mejores ejemplos de Europa Occidental lo constituyen el Día de San Patricio (17 de Marzo) en la Irlanda católica y el 17 de Mayo (en memoria de una tentativa por una constitución soberana en 1814) en Noruega. En muchas partes de Europa Oriental y Centro-Oriental, la euforia nacional se ha enfriado rápidamente bajo las frías aguas de la restauración capitalista y las celebraciones nacionales se han desdibujado, al menos por ahora.

Dejando de lado los diversos feriados nacionales, el calendario europeo contemporáneo de rituales colectivos, ceremonias y festividades es gobernado por el año de la iglesia cristiana, las conmemoraciones de las guerras mundiales y por el Día del Trabajo.

El cincuentenario del término de la guerra en Europa, proporciona una visión reciente de las distintas formas en que los principales sucesos nacionales pueden ser recordados. El gran festival popular en Gran Bretaña, con cervezas y bailes en el Hyde Park y cuyo principal centro de interés, tanto oficial como popular, es la presencia de la Dama Vera Lynn cantando canciones tales como 'Roll out the barrel' o 'The white ciffs of Dover', y la anciana abuelita de la nación, la Reina Madre, sonriendo benévolamente desde el balcón del Palacio Real, un suceso similar a las conmemoraciones populares informales de países tales como Dinamarca y Noruega.

La guerra británica fue una guerra popular, en tanto que la francesa lesionó y dividió al país a través de la derrota, la colaboración y la Resistencia. En Paris, en la ceremonia estatal de 1995, hubo un protocolo militar y diplomático estricto sin ninguna participación popular, acompañado de las palabras del presidente saliente, las que hacían referencia a la ambiguiedad de la guerra. La Alemania derrotada puso en escena en Berlín el acto estatal, austero y discursivo, recordando de manera autocrítica la guerra. En Rusia, en donde la antigua guerra tiene un nombre nacional, especial desde los tiempos del soviet, "La Gran Guerra Patriótica", hubo un intento por revivir en algo la pompa militar del Día de la Victoria Soviética, pero ahora debilitada por la manifestación pública de amargas divisiones políticas.

En años recientes, los triunfos deportivos internacionales se han convertido a menudo en eventos nacionales, en objetos de manifestaciones colectivas masivas -oficiales e informales- de alegría por las glorias de la nación. Por ejemplo, el principal evento colectivo en Finlandia en 1995 (al menos la primera mitad del mismo) fue el júbilo durante el campeonato mundial de hockey sobre hielo. La intervención de los deportes como un identificador nacional constituye una tarea futura de investigación.

La arquitectura de la ciudad capital puede ser vista como un ritual congelado, al menos en lo que concierne a los edificios públicos de gobierno y cultura. sus monumentos y su diseño del espacio central. El surgimiento de la nación y de la identidad nacional en Europa durante la Revolución francesa y las guerras napoleónicas, transformó las ciudades principales de Europa Occidental en ciudades de la nación. Inmediatamente antes de ello, la Guerra de Independencia americana llevó a la construcción de la primera capital nacional, la ciudad de Washington, adecuadamente nombrada en memoria del héroe de la nación.

Previamente, la riqueza y el poder de las ciudades se expresaba en las iglesias y con- 
ventos; en los palacios de la realeza y la nobleza y en las puertas de la ciudad, los ayuntamientos y casas de los gremios. Es decir, en mostrarios de los pilares del Estado pre-nacional y de la sociedad de estados, de la iglesia, de la dinastía y la aristocracia y do los burgueses. Las estatuas y las esculturas exteriores eran eclesiasticas y dinásticas, ocasionalmente antiguas.

La aparición de la nación trajo consigo los editicios públicos, la conmemoración de los héroes de guerra y de otras grandes figuras no reales, los espacios públicos destinados a celebrar las victorias -tanto futuras como pasadas- de la nación.

París fue pionera y campeona de esta nueva nacionalización de la ciudad capital. La vía triumphalis que se extiende desde las Tullerías, pasando por la Plaza de la Concordia hasta el Arco de Triunfo, constituye el legado más monumental del período. Planificada y comenzada por Napoleón y terminada por la Monarquía de Julio, le siguió la conmemoración del Soldado Desconocido de la Primera Guerra Mundial. Se continuó en nuestros tiempos con el homenaje al General de Gaulle, para lo cual la Plaza de LíEtoile -alrededor del Arco de Triunfo- pasó a llamarse Plaza General de Gaulle. Y recientemente, se ha prolongado el clásicamente nacionalista Camino del Triunfo mediante la erección del moderno y civil Arco de La Defensa, en línea con el anterior.

En Londres, el resultado de las guerras napoleónicas dio origen a la Plaza de Trafalgar con la Columna de Nelson, a las estatuas de Wellington, al Museo Británico y al Parlamento. Al igual que en Paris, los memoriales de las guerras del siglo XX se han agregado en forma discreta a los monumentos nacionales del siglo XIX. En Berlín, el diseño de los espacios públicos se deriva en gran parte de los últimos años del Antiguo Régimen, pero las Guerras de Liberación anti-francesas llevaron a la construcción del Nuevo Reloj de Schinkel, una pieza más bien modesta de via triumphalis situada en el Unter den Linden y al monumento nacional coronado con una Cruz de Hierro, que más tarde dió su nombre al distrito de Kreuzberg.

El París revolucionario también fue pionero en dar a la ciudad una nueva identidad política a través del cambio de nombre de las calles y de los espacios públicos. La Plaza Luis $\mathrm{XV}$, con una estatua ecuestre del rey, se convirtió en la Plaza de la Revolución con una estatua de la Libertad y luego pasó a denominarse la Plaza de la Concordia, ornamanetada con un obelisco egipcio. En los momentos álgidos de la revolución, la Plaza del Trono se convirtió en la Plaza del Trono Derrocado y luego en la Plaza de la Nación.

Las anteriores son sólo ilustraciones de cómo los rituales, los emblemas simbólicos y la arquitectura pueden ser usados como elementos para la lectura de la identidad nacional. Su estudio comparativo sistemático constituye el objetivo de un proyecto de investigación que el autor está a punto de iniciar. 